\title{
Uterine metastasis from the rectosigmoid transition cancer: a case report
}

Nicoli Taiana Henn ${ }^{1 *}$, Kelen Zanin², Bruna de Oliveira² ${ }^{2}$ Daniela Schwingel ${ }^{3}$ and Julia Pastorello'

*Correspondence: nicolihenn@yahoo.com.br

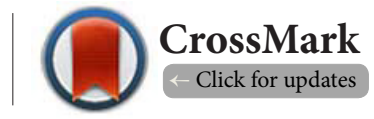

\begin{abstract}
${ }^{1}$ Medical oncologist at the Hospital City of Passo Fundo- RS- BR, Street Tiradentes, Brazil.
${ }^{2}$ Academic of the sixth semester at the Federal University of the South Frontier campus Passo Fundo-RS-BR,

Street: Bento Goncalves, Brazil.

${ }^{3}$ Pathologist at the Pathology Institute of Passo Fundo (IPPF), Rua Teixeira Soares, Brazil.
\end{abstract}

\begin{abstract}
Colorectal Cancer is common and it will often present with metastases during the course of the disease and follow-up. Usually metastasis affects liver and lungs, but other organs may also be involved. We report the case of a patient who had cancer in the recto-sigmoid transition in 2002 and had a recurrence 14 years after surgery with metastasis in the uterine body. The patient had the tumor resected and was given adjuvant chemotherapy. It is important to consider this possibility in patients with prior history of neoplasm that presents with abnormal vaginal bleeding.
\end{abstract}

Keywords: Uterus, metastasis, colon cancer

\section{Introduction}

Colorectal cancer includes tumors that affect colon segment or rectum [1]. Usually evolves from adenoma to adenocarcinoma over the years [2]. The segments most affected by this tumor are rectum and sigmoid, being followed by cecal region.

The global estimate in 2012 put the colon cancer and rectum as second most common among women and the third most common among men, and the majority (55\%) occur in countries with a high Human Development Index (HDI), unlike its mortality, more common in countries with low HDI [1].

This cancer is closely related to the population way of life, being higher when there is higher consumption of red and processed meats, low intake of fruits and vegetables, physical inactivity, obesity and overweight, and the consumption of alcohol and tobacco habit [1]. Patients with inflammatory bowel disease (Crohn's disease and ulcerative colitis) are also at increased risk of developing this neoplasm [3]. In addition, genetic syndromes increase the risk of colorectal cancer, as Lynch syndrome (hereditary cancer no polypoid) [4] and Familial adenomatous polyposis [5].

The survival rate of colon cancer changes by staging and early diagnosis and treatment. For patients with stage I disease and low-risk stage II or high frequency microsatellite instability, usually surgical resection with removal of lymph nodes in block is the only approach needed [6]. For patients with clinical stage II with high risk factors (T4, poorly differentiated histology, lymphovascular and/or perineural invasion, intestinal obstruction, positive margins or inadequate lymph node resection) after surgery, adjuvant chemotherapy may be considered generally with fluoropyrimidine alone. The patients with stage III, adjuvant therapy is recommended for six months [7] generally with fluoropyrimidine and oxaliplatin.

Some selected patients have benefit from surgery for metastasis when cure is sometimes possible, which is shown especially with liver metastasis [8].

As the progress of therapy for the disease and long-term monitoring of patients, less common sites of metastases are present, as is the case of metastasis in the uterine body. We present the case of a woman 46 years old with metastasis in uterine body from colonic adenocarcinoma.

\section{Case presentation}

A 46 years old woman of with recto-sigmoid transition adenocarcinoma history in 2002, submitted to rectosigmoidectomy with pathology staging II (T3NOMO) that received adjuvant treatment with injectable Fluoropyrimidine for six cycles, and later local radiotherapy. She remained in monitoring for five years and then she was discharged. In 2016, she experienced abnormal vaginal bleeding and sought gynecological assistance that requested a pelvic magnetic resonance, which showed small 
Henn et al. Journal of Histology \& Histopathology 2017,

http://www.hoajonline.com/journals/pdf/2055-091X-4-6.pdf

nodular formation in the fundus of the uterus and proximal segment of the endometrial cavity, exhibiting paramagnetic enhancement. She underwent hysterectomy, pathology and subsequent immunohistochemistry, which showed moderately differentiated adenocarcinoma with positive neoplastic cells in the following antibodies: CK20, CDX2 and CEA, with no positivity for antibodies: CK7, vimentin and Estrogen Receptor. Computed tomography (CT) scan showed no disease at another site and the postoperative value of carcinoembryonic antigen (CEA) was $1.5 \mathrm{ng} / \mathrm{mL}$. She had a recent colonoscopy without evidencing new lesions. It was then decided to start chemotherapy with mFOLFOX6 scheme for the patient for six months. It was done microsatellite instability research which showed immunohistochemistry positivity for MSH-2 and $\mathrm{MSH}-6$ antibodies, and no positivity for MLH-1 and PMS2 antibodies, and because of that, indicated evaluation for BRAF mutation (Figures 1-5).

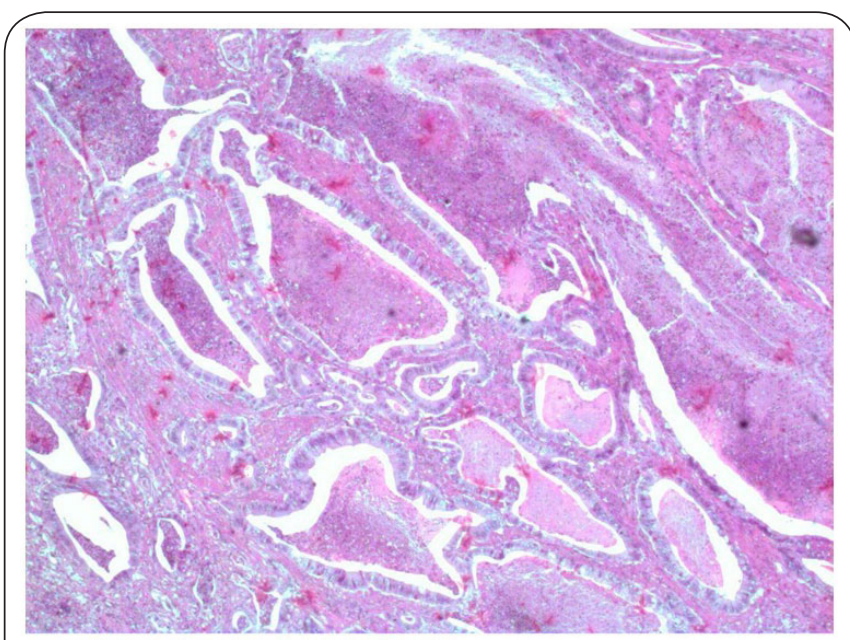

Figure 1. H\&E-2.5x-adenocarcinoma with foci of necrosis infiltrating the myometrium.

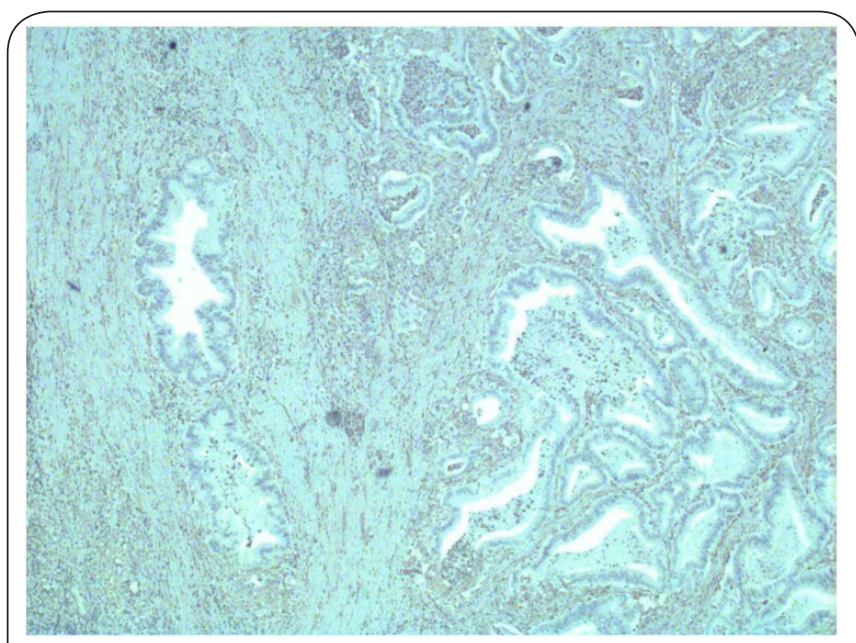

Figure 2. Immunohistochemistry $2.5 \mathrm{x}$-Vimentin-absence of marking.

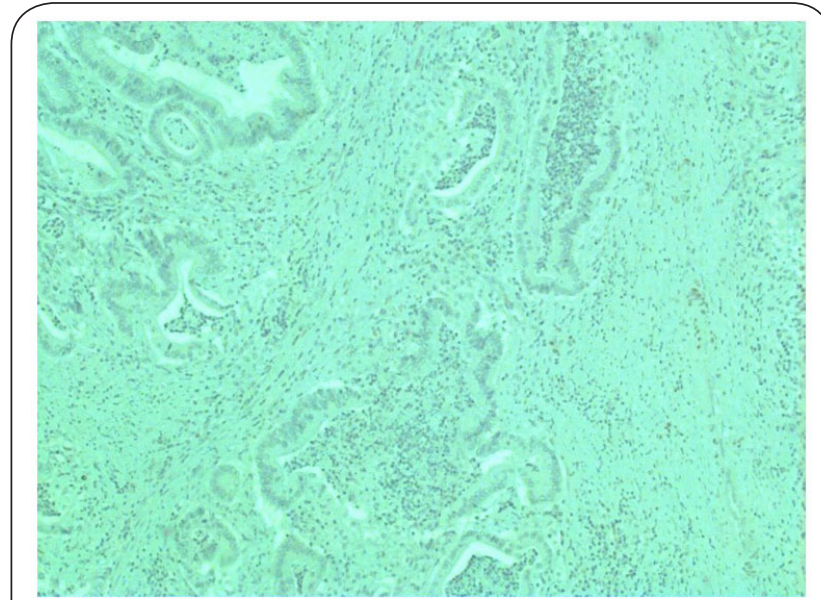

Figure 3. Immunohitochemisty 2.5x-Estrogen receptorabsence of marking.

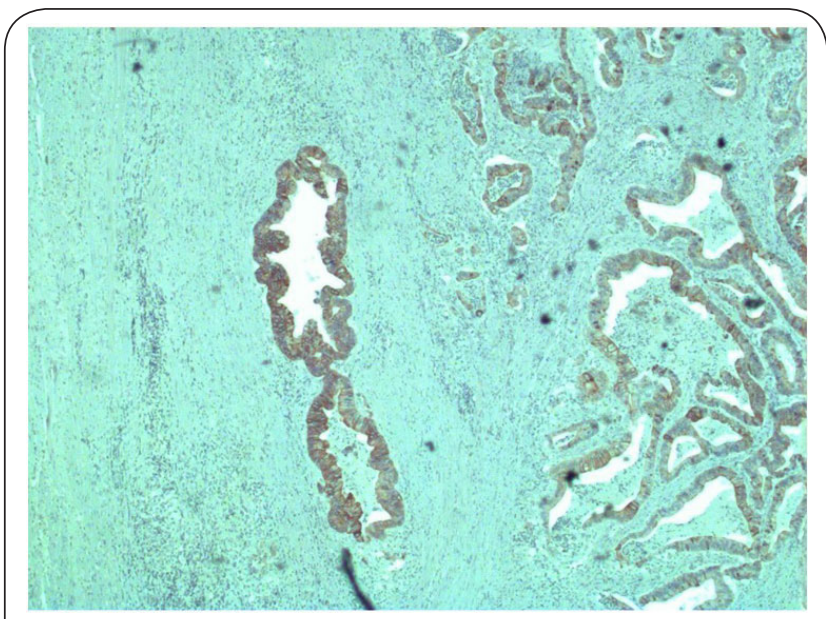

Figure 4. Immunohistochemistry 2.5x-CK20-presence of marking.

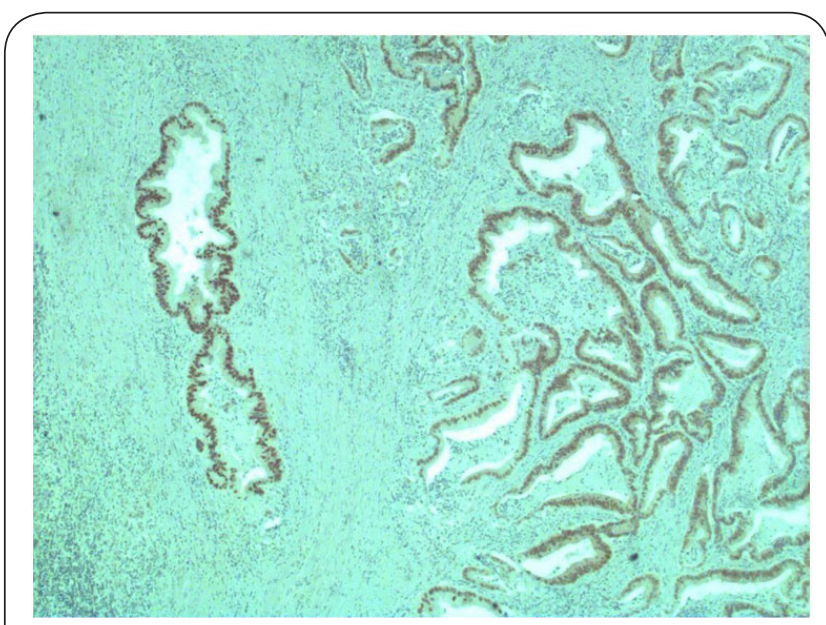

Figure 5. Immunohistochemistry 2.5x-CDX2-presence of marking. 
Henn et al. Journal of Histology \& Histopathology 2017,

\section{Discussion}

If the tumor were mucinous, it might be very difficult to distinguish between colonic origin or the female genital tract [9-12]. In the immunohistochemistry, it could have presented CK7 positive and CK20 negative even if it was from colonic origin [13], but our patient presented the most common profile in colon cancer (CK7 negative and CK20 positive).

Usually colon cancer metastases are concentrated in the liver, lymph nodes and lungs, but other sites may also be involved. When the female genital tract is affected, usually it occurs in the ovaries [14]. Metastasis to the uterine body is infrequently diagnosed. The metastasis could be in the cervix uterine, as also previously described $[15,16]$.

The oligometastatic disease can be characterized by the presence of metastasis in two or three sites, occasionally five or sometimes more lesions, particularly in viscera. In these patients, we can use local therapies to improve their outcomes. When metastatic disease is confined to an organ, a potential curative treatment exist [17].

A case of metastasis to the uterine body of a sigmoid cancer was reported by Tokoro $Y$ [18], but in this case metastasis was synchronous to the initial tumor and the diagnosis was also made only with the help of immunohistochemistry, as originally also thought to be of endometrial origin. After resection of both lesions was indicated adjuvant therapy with Xelox scheme for six months.

In a series of 63 reported cases of metastasis to the uterine body by extragenital primary neoplasms, the colon was the second most common primary site, it lost only to breast. Remember also that when the uterus is affected, usually occurs by direct extension to adjacent organs or peritoneal dissemination of ovaries carcinomas implants [14].

The patient in this case report had her primary tumor in 2002, 14 years later she had recurrence. CT scans showed no lesions elsewhere, so we opted to extrapolate postresection data to liver and lung metastases and, following the same idea than Tokoro Y, we also indicated adjuvant chemotherapy scheme based in fluoropyrimidine and oxaliplatin and the patient is tolerating well.

In addition, based on the results of immunohistochemistry in which MLH-1 and PMS2 (proteins of DNA repair) are impaired, we follow the Guidelines for Genetics evaluation and Lynch Syndrome management [19] and request search for BRAF mutation. Considering the 2002 approach, if it had the availability and knowledge of the microsatellites instability test, this patient probably would have not received chemotherapy at the time.

\section{Conclusion}

We should pay attention to patients with previous long term history of cancer if they show abnormal vaginal bleeding complaint, we must remember that there is a probability that we are facing a possible metastasis, as well as uterine primary malignancy or benign causes.

\section{Competing interests}

The authors declare that they have no competing interests.

\section{Authors' contributions}

\begin{tabular}{|l|c|c|c|c|c|}
\hline Authors' contributions & NTH & KZ & BO & DS & JP \\
\hline Research concept and design & $\checkmark$ & $\checkmark$ & $\checkmark$ & $\checkmark$ & $\checkmark$ \\
\hline Collection and/or assembly of data & $\checkmark$ & $\checkmark$ & $\checkmark$ & $\checkmark$ & -- \\
\hline Data analysis and interpretation & $\checkmark$ & -- & -- & $\checkmark$ & $\checkmark$ \\
\hline Writing the article & $\checkmark$ & $\checkmark$ & $\checkmark$ & -- & -- \\
\hline Critical revision of the article & $\checkmark$ & -- & -- & -- & $\checkmark$ \\
\hline Final approval of article & $\checkmark$ & $\checkmark$ & $\checkmark$ & $\checkmark$ & $\checkmark$ \\
\hline
\end{tabular}

Acknowledgement

We thank the patient who allowed the publication of her case.

Publication history

Editor: Stefano Fratoni, St.Eugenio Hospital of Rome, Italy. Received: 12-Mar-2017 Final Revised: 15-Apr-2017 Accepted: 05-May-2017 Published: 19-May-2017

\section{References}

1. National Cancer Institute José Alencar Gomes da Silva (INCA). Estimate/2016-Cancer Incidence in Brazil. 2015; 1:1-126. | Pdf

2. Gastaldo K, Rossin FM, Navarro P, de Sá CC and Navarro-Rodriguez T. How to Diagnose and Treat Colon Cancer. 2006; 63: 511-7. I Website

3. Beaugerie L, Svrcek M, Seksik P, Bouvier AM, Simon T, Allez M, Brixi H, Gornet JM, Altwegg R, Beau P, Duclos B, Bourreille A, Faivre J, PeyrinBiroulet L, Flejou JF and Carrat F. Risk of colorectal high-grade dysplasia and cancer in a prospective observational cohort of patients with inflammatory bowel disease. Gastroenterology. 2013; 145:166-175 e8. | Article I PubMed

4. Lynch HT and de la Chapelle A. Hereditary Colorectal Cancer. N Engl J Med. 2003; 348:919-32. I Article

5. Galiatsatos $P$ and Foulkes WD. Familial adenomatous polyposis. Am J Gastroenterol. 2006; 101:385-98. I Article

6. National Comprehensive Cancer Network (NCCN). Colon Cancer. 2016; 1-175. | Pdf

7. Des Guetz G, Uzzan B, Morere JF, Perret G and Nicolas P. Duration of adjuvant chemotherapy for patients with non-metastatic colorectal cancer. Cochrane Database Syst Rev. 2010; CD007046. | Article | PubMed

8. Kemeny N. Management of liver metastases from colorectal cancer. Oncology (Williston Park). 2006; 20:1161-76, 1179. | Article | PubMed

9. Park KJ, Bramlage MP, Ellenson LH and Pirog EC. Immunoprofile of adenocarcinomas of the endometrium, endocervix, and ovary with mucinous differentiation. Appl Immunohistochem Mol Morphol. 2009; 17:8-11. | Article | PubMed

10. Zheng W, Yang GC, Godwin TA, Caputo TA and Zuna RE. Mucinous adenocarcinoma of the endometrium with intestinal differentiation: a case report. Hum Pathol. 1995; 26:1385-8. I Article I PubMed

11. McCluggage WG, Roberts $\mathrm{N}$ and Bharucha $\mathrm{H}$. Enteric differentiation in endometrial adenocarcinomas: a mucin histochemical study. Int J Gynecol Pathol. 1995; 14:250-4. I Article I PubMed

12. Buell-Gutbrod R, Sung CJ, Lawrence WD and Quddus MR. Endometrioid adenocarcinoma with simultaneous endocervical and intestinal-type mucinous differentiation: report of a rare phenomenon and the immunohistochemical profile. Diagn Pathol. 2013; 8:128. | Article | PubMed Abstract | PubMed FullText

13. Toyoshima M, Momono Y, Makino H, Kudo T, Oka N, Sakurada J, Suzuki $\mathrm{H}$, Kodama $\mathrm{H}$ and Yoshinaga K. Cytokeratin 7-positive/cytokeratin 20-negative cecal adenocarcinoma metastatic to the uterine cervix: a case report. World J Surg Oncol. 2016; 14:22. | Article | PubMed Abstract I PubMed FullText 
Henn et al. Journal of Histology \& Histopathology 2017,

http://www.hoajonline.com/journals/pdf/2055-091X-4-6.pdf

14. Kumar NB and Hart WR. Metastases to the uterine corpus from extragenital cancers. A clinicopathologic study of 63 cases. Cancer. 1982; 50:2163-9. | Article | PubMed

15. Berhili S, El Khannoussi B, Kadiri S, Mezouri I, Bazine A, Touil A, El Khiyat I, Kebdani T and Benjaafar N. Uterine cervix metastasis from a sigmoid adenocarcinoma: a rare presentation of an uncommon tumor. Gynecol Oncol Res Pract. 2014; 1:6. | Article | PubMed Abstract | PubMed FullText

16. Kapoor R, Khosla D, Gupta R, Srinivasan R, Bahl A, Kumar R and Sharma $S C$. Uterine cervix metastasis from primary colorectal carcinoma: a report of two cases with review of literature. J Gastrointest Cancer. 2013; 44:231-3. | Article | PubMed

17. Van Cutsem E, Cervantes A, Adam R, Sobrero A, Van Krieken JH, Aderka D, Aranda Aguilar E, Bardelli A, Benson A, Bodoky G, Ciardiello F, D'Hoore A, Diaz-Rubio E, Douillard JY, Ducreux M, Falcone A and Grothey A et al. ESMO consensus guidelines for the management of patients with metastatic colorectal cancer. Ann Oncol. 2016; 27:1386-422. | Article | PubMed

18. Tokoro $\mathrm{Y}$, Tonooka T, Souda H, Takiguchi N, Chibana T, Kobayashi R, Arimitsu H, Yanagibashi H, Chou A, Ikeda A, Nabeya N, Kainuma O, Yamamoto $\mathrm{H}$ and Nagata M. [A Case of Sigmoid Colon Cancer with Metastasis to the Uterus]. Gan To Kagaku Ryoho. 2015; 42:1662-4. | PubMed

19. Giardiello FM, Allen JI, Axilbund JE, Boland CR, Burke CA, Burt RW, Church JM, Dominitz JA, Johnson DA, Kaltenbach T, Levin TR, Lieberman DA, Robertson DJ, Syngal $S$ and Rex DK. Guidelines on genetic evaluation and management of Lynch syndrome: a consensus statement by the US Multi-society Task Force on colorectal cancer. Am J Gastroenterol. 2014; 109:1159-79. | Article | PubMed

\section{Citation:}

Henn NT, Zanin K, de Oliveira B, Schwingel D and Pastorello J. Uterine metastasis from the rectosigmoid transition cancer: a case report. J Histol Histopathol. 2017; 4:6. http://dx.doi.org/10.7243/2055-091X-4-6 